Mindestlohn

\section{Euro sind möglich und nötig}

2020 verspricht einmal mehr ein Jahr des Mindestlohns zu werden. Ein breites politisches Spektrum aus Gewerkschaften, Sozialverbänden, Linken, Grünen, SPD und sogar Teilen der CDU plädiert mittlerweile für eine deutliche Erhöhung des Mindestlohns, die über die turnusgemäße Anpassung an die Tariflohnentwicklung hinausgeht. Hierbei haben sich 12 Euro als neue Zielmarke etabliert. Umfragen zufolge unterstützt eine großen Mehrheit der Bevölkerung einen Mindestlohn von 12 Euro.

Als vor fünf Jahren in Deutschland erstmals ein gesetzlicher Mindestlohn eingeführt wurde, stand die grundlegende Überzeugung dahinter, dass Arbeit nicht arm machen darf und ein existenzsicherndes Einkommen garantieren muss. In der ursprünglichen Begründung des Mindestlohngesetzes wurde explizit darauf verwiesen, dass nicht existenzsichernde Löhne durch staatliche Leistungen aufgestockt werden müssen und Unternehmen auf diese Weise indirekt durch die sozialen Sicherungssysteme subventioniert werden. Seit Einführung des Mindestlohns hat sich die Zahl der "Aufstocker" allerdings nur wenig verändert, während Deutschland nach wie vor über einen der größten Niedriglohnsektoren in Europa verfügt. Vor diesem Hintergrund will die Forderung nach 12 Euro Mindestlohn nun das erfüllen, was der Mindestlohn von Anfang an versprochen hatte: Einen Lohn, mit dem man zumindest bei einer Vollzeitstelle einigermaßen über die Runden kommen kann.

Schon bei der Einführung des Mindestlohns war klar, dass mit der Einstiegsmarke von 8,50 Euro kein existenzsichernder Lohn geschaffen wurde. Hinzu kommt ein Anpassungsmechanismus, der mit der Mindestlohnkommission und der vorgegebenen Orientierung an den Tariflöhnen so konstruiert ist, dass strukturelle Mindestlohnerhöhungen nahezu ausgeschlossen sind. Das niedrige Einstiegsniveau war vor allem das Ergebnis einer weit verbreiteten Unsicherheit über die ökonomischen Folgen des Mindestlohns. Mit ihrer mehrheitlich ablehnenden Position und ihren teilweise abenteuerlichen Beschäftigungsprognosen hat die deutsche Wirtschaftswissenschaft entscheidend zu dieser Unsicherheit beigetragen. Aus heutiger Sicht herrscht weitgehende Einigkeit, dass der Mindestlohn zu keinen nennenswerten Jobverlusten ge-

(c) Der/die Autor(en) 2020. Open Access: Dieser Artikel wird unter der Creative Commons Namensnennung 4.0 International Lizenz (https:// creativecommons.org/licenses/by/4.0/deed.de) veröffentlicht.

Open Access wird durch die ZBW - Leibniz-Informationszentrum Wirtschaft gefördert. führt hat. Stattdessen haben die Unternehmen eine Vielzahl von anderen Reaktionsmöglichkeiten ausgeschöpft. Hierzu gehören u.a. höhere Preise, niedrigere Gewinne, eine höhere Produktivität und die Durchsetzung innovativerer Geschäftsmodelle. Manche Unternehmen haben es auch vorgezogen, den Mindestlohn auf illegale Weise zu umgehen, wobei es keineswegs ausgemacht ist, ob diese Unternehmen den Mindestlohn nicht zahlen können oder einfach nicht zahlen wollen.

Nun kann aus den bisherigen Erfahrungen natürlich nicht einfach abgeleitet werden, dass auch eine Erhöhung auf 12 Euro ohne jegliche Auswirkungen auf die Beschäftigung bleiben würde. Von einem solchen Schritt wären etwa 10 Mio. Beschäftigte betroffen und damit mehr als doppelt so viele wie bei der Einführung des Mindestlohns. Auch der Zuwachs von derzeit 9,35 Euro wäre mit mehr als $28 \%$ nicht gerade unerheblich. Allerdings deutet die Entwicklung auf dem deutschen Arbeitsmarkt darauf hin, dass es in vielen Bereichen durchaus noch erhebliche Spielräume für höhere Löhne gibt. Während die Gefahr von Arbeitsplatzverlusten derzeit vor allem in einigen industriellen Hochlohnbranchen besteht, wird in vielen klassischen Niedriglohnbranchen wie z.B. der Landwirtschaft, dem Bäcker- und Friseurhandwerk oder dem Hotel- und Gaststättengewerbe händeringend Personal gesucht. Mit einem höheren Mindestlohn könnten gerade diese Branchen deutlich aufgewertet und damit für Beschäftigte wieder attraktiver werden.

Neuere internationale Mindestlohnstudien zeigen, dass deutlich höhere Mindestlöhne keineswegs automatisch zu Beschäftigungsverlusten führen müssen. Erst unlängst kam der international renommierte Arbeitsökonom Arindrajit Dube in einer Überblicksstudie für die Regierung in Großbritannien zu dem Ergebnis, dass Mindestlöhne durchaus auf $60 \%$ bis $66 \%$ des jeweiligen nationalen Medianlohns angehoben werden können, ohne dass hierdurch in nennenswertem Ausmaß negative Beschäftigungseffekte eintreten müssen. Derzeit liegt der deutsche Mindestlohn bei weniger als $50 \%$ des Medianlohns. Mit einer Erhöhung auf $60 \%$ würde ziemlich genau die Marke von 12 Euro erreicht werden. Um den Unternehmen etwas mehr Zeit für die Anpassung zu geben, könnte die Erhöhung auf 12 Euro schrittweise vorgenommen werden: Denkbar wäre z. B. den Mindestlohn ab 2021 auf zunächst 10 Euro und dann in den beiden Folgejahren um jeweils 1 Euro anzuheben, sodass ab 2023 der Mindestlohn bei 12 Euro liegen würde.

Thorsten Schulten WSI - Wirtschafts- und Sozialwissenschaftliches Institut thorsten.schulten@boeckler.de 